\title{
Phase I and pharmacokinetic study of TSU-68, a novel multiple receptor tyrosine kinase inhibitor, by twice daily oral administration between meals in patients with advanced solid tumors
}

\author{
Yutaka Ueda • Tatsu Shimoyama • \\ Haruyasu Murakami · Noboru Yamamoto · \\ Yasuhide Yamada $\cdot$ Hitoshi Arioka $\cdot$ Tomohide Tamura \\ Received: 10 February 2010 / Accepted: 11 July 2010 / Published online: 30 July 2010 \\ (C) The Author(s) 2010. This article is published with open access at Springerlink.com
}

\begin{abstract}
Purpose A single-agent dose-escalating phase I and pharmacokinetic study on TSU-68, a novel multiple receptor tyrosine kinase inhibitor, was performed to determine the safety profile, maximum-tolerated dose for Japanese patients with advanced solid tumors and to define the recommended dose of phase II studies.

Methods Study design was a dose escalation method on a three-patient cohort. TSU-68 was given orally twice daily (bid) between meals without interruption; the estimation of dose escalation was based on the toxicity within 4 week administration at each dose level.
\end{abstract}

Y. Ueda $\cdot$ T. Shimoyama $\cdot$ H. Murakami $\cdot$ N. Yamamoto

Y. Yamada $\cdot$ T. Tamura $(\bowtie)$

Division of Medical Oncology,

National Cancer Center Hospital, 5-1-1, Tsukiji,

Chuo-ku, Tokyo 104-0045, Japan

e-mail: ttamura@ncc.go.jp

H. Arioka

Department of Medical Oncology,

Yokohama Rosai Hospital,

Yokohama, Kanagawa, Japan

Y. Ueda

Department of Internal Medicine,

Kagawa Prefectural Central Hospital, Takamatsu,

Kagawa, Japan

T. Shimoyama

Department of Chemotherapy,

Tokyo Metropolitan Cancer and Infectious Diseases

Center Komagome Hospital, Tokyo, Japan

H. Murakami

Thoracic Oncology Division,

Shizuoka Cancer Center, Shizuoka, Japan
Results Fifteen patients were enrolled into the study. Dose levels studied were $200,400,800$, and $1,200 \mathrm{mg} / \mathrm{m}^{2}$ bid. Grade 3 arrhythmia and anemia/thrombocytopenia were observed in 1 patient each at $800 \mathrm{mg} / \mathrm{m}^{2}$ bid. Three patients discontinued continuous oral administration for 4 weeks at 400 and $800 \mathrm{mg} / \mathrm{m}^{2}$ bid. At $1,200 \mathrm{mg} / \mathrm{m}^{2}$ bid, 2 patients discontinued the treatment over 4 weeks for intolerable fatigue and abdominal pain, respectively. No serious drug-related toxicities have been observed. Grade 1-2 toxicity included urinary/feces discoloration, diarrhea, fatigue, anorexia, abdominal/chest pain, and edema. Tumor shrinkage was observed in 1 patient of NSCLC. In the pharmacokinetics, at any dose levels, $\mathrm{C}_{\max }$ and $\mathrm{AUC}_{0-\mathrm{t}}$ after repeated administration of TSU-68 on days 8 and 29 were $\sim 2$-fold lower that those after the first administration on day 1 ; these parameters are similar between days 8 and 28. In addition, no obvious dose-dependent increase in plasma exposure to TSU-68 repeatedly administered was observed over the four dose levels, including the higher dose levels.

Conclusions The tolerable dose in this administration schedule for continuing treatment is thought to be $800 \mathrm{mg} / \mathrm{m}^{2}$ or less bid.

Keywords Receptor tyrosine kinase inhibitor . Solid tumors · Phase I · Pharmacokinetic

\section{Introduction}

Angiogenesis, the growth of new blood vessels from existing host vasculature, plays a central role in a variety of physiologic and pathologic states. Several families of RTKs such as vascular endothelial growth factor (VEGF), fibroblast growth factor (FGF), and platelet-derived growth factor (PDGF) receptors have been implicated in this process and 
are involved in diverse developmental and oncogenic processes. VEGF has been shown to be the central positive regulator of tumor angiogenesis, since it is reported that the production of VEGF may be increased in many solid tumors and the ability of production may be correlated with the number of blood vessels and prognosis in breast caner, stomach cancer, colon cancer, lung cancer, and others [1-4]. VEGF signaling is an attractive therapeutic target, and the antibodies and inhibitors specifically directed against VEGF and/or its receptor VEGFR2 have been demonstrated to potently prevent vasculature and the growth of a large number of experimental tumor types [5, 6]. FGF and PDGF also play critical roles in angiogenesis, sometimes in concert with VEGF. The prototype FGF family member, FGF2, is a potent mitogen of different cell types including vascular endothelial cells, fibroblasts, and tumor cells, along with its receptors, in a variety of human tumor types $[7,8]$. Additionally, FGF2 has been reported to be synergistic with VEGF and to induce the expression of VEGF [9]. FGF is one of the alternative angiogenesis factors during the resistance of VEGF-targeting therapy. PDGF and its receptors have been detected in diverse human cancers, and PDGFRs are expressed on tumor neovasculature and upregulated during tumor progression [10, 11]. PDGF stimulates angiogenesis by up-regulating VEGF production and modulating the proliferation of pericytes and fibroblast-like cells surrounding the endothelium [12, 13]. Circulating PDGF has been associated with metastases and higher microvessel counts $[14,15]$.

The signaling cascades generated by these three ligands and their respective receptors are complex, directly and indirectly affecting tumor angiogenesis and tumor growth. In light of the important role of VEGF, FGF, and PDGF and their receptors in tumor angiogenesis and in survival of existing endothelial cells, it is reasonable to expect that simultaneously antagonizing the VEGF, FGF, and PDGF signaling pathways may be more effective than antagonizing one signal transduction alone. TSU-68 is a novel small molecule that competitively inhibits the tyrosine kinase of the receptors for VEGF, basic FGF, and PDGF. TSU-68 has significant antitumor activity against many types of tumor xenograft explants in athymic mice [16]. TSU-68 inhibits angiogenesis through several mechanisms, including the induction of apoptosis in vascular endothelial cells and tumor cells, resulting in perturbing existing tumor vascular function and also inhibiting newly synthesis angiogenesis for the tumor growth [17].

On the basis of these preclinical antiangiogenic and antitumor data, we planned a phase I study of TSU-68 in patients with advanced solid tumors using a continuous twice daily between meals oral administration regimen.

\section{Patients and methods}

Study population

Patients with a cytologically or histologically confirmed diagnosis of a solid tumor refractory to standard treatment or for whom no standard therapy was available were eligible for this study. Patients with symptomatic brain metastases were excluded. Further eligibility criteria included the following: age $\geq 20$ years and $\leq 75$ years; World Health Organization performance status of $\leq 2$; life expectancy of $\geq 60$ days; no anticancer therapy in the previous 4 weeks; no serious complication (ileus, myocardial infarction, lung fibrosis, and so on); no past history of thrombosis; adequate function of bone marrow (hemoglobin $\geq 8.0 \mathrm{mg} / \mathrm{dl}$, absolute white blood cell count $\geq 4,000 /$ $\mathrm{mm}^{3}$ or neutrophil count $\geq 2,000 / \mathrm{mm}^{3}$, and white blood cell count $\leq 12,000 / \mathrm{mm}^{3}$ ); liver (bilirubin $\leq 1.5 \mathrm{mg} / \mathrm{dl}$; AST and ALT $\leq 100 \mathrm{IU} / \mathrm{ml}$ ); renal (creatinine clearance $\geq 50 \mathrm{ml} / \mathrm{min})$; lung $\left(\mathrm{PaO}_{2} \geq 65 \mathrm{mmHg}\right)$; and ability to take oral medication. Local ethics boards approved the protocol and informed-consent brochures in accordance with the Declaration of Helsinki and Good Clinical Practice Guidelines. All patients gave written informed consent at study entry.

\section{Study design}

This study was an open, non-randomized, non-comparative, dose-escalation method on three-patient cohort to adult patients with advanced solid tumors. The trial was designed to comply with the ethical principals of Good Clinical Practice in accordance with the Declaration of Helsinki.

The estimation of dose escalation was based on the toxicity within 4 week administration at each dose level. If no grade 2 toxicity was observed at the previous dose level, a $100 \%$ dosage increment was allowed, and if no dose-limiting toxicity (DLT) was observed, a $40 \%$ dosage increment was allowed. However, if DLT was observed, a 33\% dosage increment was allowed. At each dose level, the third patient was required to have 14 days of treatment before escalation was allowed. Once DLT was seen in one patient at a given dose level, an additional 3 patients had to be treated at that dose level before further dose escalation was allowed. DLT was defined as drug-related adverse events according to National Cancer Institute-Common Toxicity Criteria version 2.0 (NCI-CTC) [18] and comprised any grade 3/4 non-hematologic toxicity and grade 4 hematologic toxicity. The maximum-tolerated dose (MTD) was defined as the dose that induced DLTs in more than $33 \%$ of patients during 4 weeks. No intra-patient dose escalation was allowed. 
Drug administration

TSU-68, (Z)-3-[2,4-dimethyl-5-(2-oxo-1,2-dihydro-indol3-ylidenemethyl)-1H-pyrrol-3-yl]-propionic acid was obtained from Taiho Pharmaceutical Co., Ltd. The starting dosing (200 mg/m $\mathrm{m}^{2}$ twice daily) of Japanese patients was calculated based on the safety results of 4 week toxicology studies in rats and referred to the precedence phase I study of Caucasian patients. At the first day of treatment, patients were given a single dose for pharmacokinetic purposes. The tablet was swallowed immediately more than $2 \mathrm{~h}$ after breakfast and supper. Patients were instructed to record their daily amount of tablets taken, the timing in relation to their meals. TSU-68 was taken for 28 consecutive days and was continued in case of stable disease or disease remission after this period for as long as no disease progression and/or no unacceptable drug-related toxicity were seen. Routine antiemetics were not prescribed. TSU-68 administration was immediately interrupted at the occurrence of DLT.

\section{Patient assessment and follow-up treatment}

Before therapy, a complete medical history was taken and a physical examination was performed. A complete blood count, including WBC differential, and serum chemistry, including sodium, potassium, chloride, calcium, urea, creatinine, protein, albumin, bilirubin, aspartate aminotransferase, alanine aminotransferase, alkaline phosphatase, gamma-glutamyl transpeptidase, and lactate dehydrogenase, were performed, as were urine analysis, Electrocardiogram, and Chest $\mathrm{X}$-ray. In addition, tumor markers related to the tumor type were measured. Weekly evaluations included history, physical examination, a toxicity assessment according to NCICTC, complete blood count, serum chemistries, and urine analysis. Tumor measurements were performed before treatment, at 4 weeks, and were evaluated according to the Japan Society for Cancer Therapy criteria [19], which was established based on World Health Organization (WHO) criteria. The criteria for the evaluation of antitumor effects were as follows: complete response (CR), eradication of all cancers and maintenance of the condition for 4 weeks or more; partial response (PR), $50 \%$ or more reduction in size of lesions and maintenance of the condition for 4 weeks or more; no change (NC), less than $50 \%$ reduction in size of lesions or enlargement of lesions within $25 \%$ and maintenance of the condition for 4 weeks or more; progressive disease (PD), $25 \%$ or more enlargement of lesions or appearance of new lesions. In case of progressive disease, patients were taken off the study.

\section{Pharmacokinetic and biomarker sampling}

For the pharmacokinetic evaluation, TSU-68 was administered once a day on days 1 and 29 and twice a daily during days 2-28. Blood samples were collected within about 30 min before dosing and at 1, 1.5, 2, 2.5, 3, 3.5, 4, 6, 8, and $12 \mathrm{~h}$ after dosing on days 1, 8 and 29. Regarding days 1 and 29 , blood samples were also collected at $24 \mathrm{~h}$ after dosing. These samples were immediately centrifuged at 3,000 rpm for $10 \mathrm{~min}$ at $4^{\circ} \mathrm{C}$, after which obtained plasma samples were frozen at $-20^{\circ} \mathrm{C}$ until analysis. Urine samples were collected at the following intervals for measurement of TSU-68: before dosing on day 1, 0-12 and 12-24 h after dosing on days 1 and 29 and $0-12 \mathrm{~h}$ after the 1 st dosing on day 8. In addition, angiogenesis-related factors such as plasma VEGF, E-selectin, tissue-type plasminogen activator (tPA), vascular cell adhesion molecule-1 (VCAM-1), plasminogen activator inhibitor-1 (PAI-1), and urine VEGF were measured on days 1,8 , and 29 .

\section{Pharmacokinetic and biomarker analyses}

The pharmacokinetic samples were measured by MDS Pharma Services (Montreal, Canada), and biomarker samples were measured by SRL, Inc. (Tokyo, Japan). TSU-68 concentration was determined using a validated high-performance liquid chromatography method with UV detection, with a lower limit of quantification of $0.1 \mu \mathrm{g} / \mathrm{mL}$. Non-compartmental pharmacokinetic parameters including area under the plasma concentration-time curves (AUC) from time 0 to the last measurable time $\left(\mathrm{AUC}_{0-\mathrm{t}}\right)$, maximum concentration $\left(\mathrm{C}_{\max }\right)$, time to maximum concentration $\left(\mathrm{T}_{\max }\right)$, and elimination half-life $\left(\mathrm{T}_{1 / 2}\right)$ were calculated using PhAST (Ver.2.3, MDS Pharma Services, Montreal, Canada).

Statistical analysis

A regression approach was applied to evaluate dose proportionality in pharmacokinetic parameters. Variability in pharmacokinetics between administration days was evaluated by either the paired Student's t-test or an analysis of variance. Statistical significance was considered to be reached at $P<0.05$. The analysis was performed using the SAS $^{\circledR}$.

\section{Results}

Patient characteristics

Fifteen patients were enrolled in this study between November 2000 and June 2001. All patients were Japanese. Details of dosage level were 3 patients at $200 \mathrm{mg} / \mathrm{m}^{2}$ bid, 3 patients at $400 \mathrm{mg} / \mathrm{m}^{2} \mathrm{bid}, 6$ patients at $800 \mathrm{mg} / \mathrm{m}^{2}$ bid, and 3 patients at $1,200 \mathrm{mg} / \mathrm{m}^{2}$ bid. Patient characteristics are listed in Table 1 . There were 5 men and 10 women with a 
Table 1 Patients characteristics

\begin{tabular}{lll}
\hline Characteristic & & $\begin{array}{l}\text { Patients number }(\%) \\
(15 \text { patients })\end{array}$ \\
\hline Gender & & $(33)$ \\
Male & 5 & $(67)$ \\
Female & 10 & \\
Age (Years) & & \\
Median & 52.0 & \\
Range & $27-64$ & \\
Performance status & & $(7)$ \\
0 & 1 & $(93)$ \\
1 & 14 & $(0)$ \\
2 & 0 & \\
Tumor type & & $(40)$ \\
NSCLC & 6 & $(20)$ \\
Colorectal & 3 & $(13)$ \\
Thymoma & 2 & $(27)$ \\
Others* & 4 &
\end{tabular}

* Including cervical cancer, retroperitoneal cancer, intestinal cancer and sarcoma of uterus

median age of 52 years (range, 27-64 years). All patients were evaluated for safety and pharmacokinetic analyses. Three patients discontinued continuous oral administration for 4 weeks due to adverse events (one patient at $800 \mathrm{mg}$ / $\mathrm{m}^{2}$ ) and disease progress (two patients at $400 \mathrm{mg} / \mathrm{m}^{2}$ and $800 \mathrm{mg} / \mathrm{m}^{2}$ ). In addition, five patients continued the medication after 4 weeks, and these included two patients of dose reduction from $1,200 \mathrm{mg} / \mathrm{m}^{2}$ to $800 \mathrm{mg} / \mathrm{m}^{2}$.

Dose escalation and maximum-tolerated dose

The dosage was increased from 200 to 400, 800, and $1,200 \mathrm{mg} / \mathrm{m}^{2}$ bid by cohort of three patients. At a dosage level of $1,200 \mathrm{mg} / \mathrm{m}^{2}$ bid, two patients discontinued the treatment over 4 weeks for intolerable grade 2 fatigue or grade 2 abdominal pain, which were not critical in evaluating the dose escalation for 4 weeks. These two patients of grade 2 toxicities could continue drug administration for 4 weeks (one cycle); however, both patients had to reduce the dosage level to $800 \mathrm{mg} / \mathrm{m}^{2}$ bid from the next cycle, and $1,200 \mathrm{mg} / \mathrm{m}^{2}$ bid demonstrated unacceptable adverse events for an antitumor drug that is used by long-term consecutive oral administration. On the basis of the results of the pharmacokinetic data, increase in the dosage was terminated, and the three additional patients were administered at a lower dosage of $800 \mathrm{mg} / \mathrm{m}^{2}$ bid. At a dosage level of $800 \mathrm{mg} / \mathrm{m}^{2}$ bid, one patient was confirmed DLT into a total of six patients. In addition, two patients at $1,200 \mathrm{mg} / \mathrm{m}^{2}$ could continue TSU-68 administration with a reduction to $800 \mathrm{mg} / \mathrm{m}^{2}$ after 4 weeks. Thus, protocol-defined MTD was
$1,200 \mathrm{mg} / \mathrm{m}^{2}$ bid, and the acceptable dosage level was estimated $800 \mathrm{mg} / \mathrm{m}^{2}$ bid in daily administration.

Dose-limiting toxicity and safety profile

There was one protocol-defined DLT as grade 3 arrhythmia at the dosage level of $800 \mathrm{mg} / \mathrm{m}^{2}$ bid. The patient had a complication with supraventricular arrhythmia but had already been controlled by continuous administration of an antiarrhythmic agent. No other DLTs were recorded.

The major drug-related adverse events for 4 week administration with highest grade pre-event per patient are listed in Table 2. Main toxicities of subjective and objective symptom were diarrhea, fatigue, anorexia, nausea, and vomiting. At lower doses, these symptoms were usually mild and required no specific treatment. Six patients experienced grade 1/2 tumor pain in diverse pain events. Edema and/or pleural effusion progression were seen in 7 patients. In addition, other toxicities consisted of grade 1 urinary/feces discoloration based on drug color (such as saffron yellow).

Drug-related abnormal changes in laboratory values were observed in grade 3 anemia and thrombocytopenia from day 27 in one patient at $800 \mathrm{mg} / \mathrm{m}^{2}$ bid. Other toxicities experienced in laboratory values were grade $1 / 2$ hypoalbuminemia, grade 1 alkaline phosphatase elevation, and transient grade 1 transaminase elevation.

Four episodes of atrial rhythm abnormalities (atrial fibrillation in a patient and sinus tachycardia in 3 patients with previous cardiac history) were seen. Each patient at $200 \mathrm{mg} / \mathrm{m}^{2}$ or $1,200 \mathrm{mg} / \mathrm{m}^{2}$ experienced grade 2 supraventricular arrhythmia or grade 1 arrhythmia; these events were of a transient manner, and there was no relationship to TSU-68. One patient of grade 3 supraventricular arrhythmia at $800 \mathrm{mg} / \mathrm{m}^{2}$ and one patient of grade 2 atrial fibrillation and grade 1 sinus tachycardia at $1,200 \mathrm{mg} / \mathrm{m}^{2}$ were treated with medication, and there was a relationship to TSU-68. One patient of grade 3 supraventricular arrhythmia (DLT) with sinus tachycardia (heart rate over 160/min) occurred on day 6 , although this patient had taken verapamil for a long time. TSU-68 treatment was discontinued, and he was treated with digoxin in addition to verapamil dose-up. Subsequently, heart rate was decreased to about 80/min.

\section{Pharmacokinetics}

Pharmacokinetic studies were performed in 15 patients at doses from 200 to $1,200 \mathrm{mg} / \mathrm{m}^{2}$. The mean concentrationtime profiles in each dosage are shown in Fig. 1. Pharmacokinetic results are presented in Table 3 . The relationship between the dose and mean $\mathrm{C}_{\max }$ or $\mathrm{AUC}_{0-\mathrm{t}}$ is plotted in Fig. 2. After the first dose, the plasma concentration of 
Table 2 Number of patients with drug-related adverse events for 28-days administration (highest grads per event per patients)

\begin{tabular}{|c|c|c|c|c|c|c|c|c|c|c|c|c|c|c|c|c|}
\hline \multirow[t]{2}{*}{ Adverse events } & \multicolumn{3}{|c|}{$\begin{array}{l}200 \mathrm{mg} / \mathrm{m}^{2} \\
\operatorname{bid}(N=3)\end{array}$} & \multicolumn{3}{|c|}{$\begin{array}{l}400 \mathrm{mg} / \mathrm{m}^{2} \\
\text { bid }(N=3)\end{array}$} & \multicolumn{3}{|c|}{$\begin{array}{l}800 \mathrm{mg} / \mathrm{m}^{2} \\
\operatorname{bid}(N=6)\end{array}$} & \multicolumn{3}{|c|}{$\begin{array}{l}1,200 \mathrm{mg} / \mathrm{m}^{2} \\
\operatorname{bid}(N=3)\end{array}$} & \multicolumn{2}{|c|}{$\begin{array}{l}\text { Total* } \\
(N=15)\end{array}$} & \multicolumn{2}{|c|}{$\begin{array}{l}\text { Total** } \\
(N=5)\end{array}$} \\
\hline & $\overline{\mathrm{G} 1}$ & G2 & G3 & G1 & G2 & G3 & G1 & G2 & G3 & G1 & $\mathrm{G} 2$ & G3 & $N$ & $(\%)$ & $N$ & $(\%)$ \\
\hline Urine discoloration & 3 & - & - & 3 & - & - & 6 & - & - & 3 & - & - & 15 & $(100)$ & 5 & $(100)$ \\
\hline Diarrhea & 3 & - & - & 1 & - & - & 2 & 2 & - & 1 & 1 & - & 10 & (67) & 3 & $(60)$ \\
\hline Feces discolored & - & - & - & 1 & - & - & 6 & - & - & 3 & - & - & 10 & $(67)$ & 4 & (80) \\
\hline Fatigue & 1 & - & - & 1 & - & - & 3 & 1 & - & 2 & 1 & - & 9 & $(60)$ & 4 & $(80)$ \\
\hline Anorexia & - & - & - & - & - & - & 3 & 1 & - & 2 & 1 & - & 7 & $(47)$ & 1 & $(20)$ \\
\hline Abdominal pain & - & - & - & - & - & - & 2 & 1 & - & 1 & 1 & - & 5 & (33) & 1 & $(20)$ \\
\hline Face edema & 1 & - & - & 1 & - & - & 1 & - & - & 2 & - & - & 5 & (33) & 3 & $(60)$ \\
\hline Nausea & 1 & - & - & - & - & - & 2 & - & - & - & 1 & - & 4 & (27) & 1 & $(20)$ \\
\hline Upper abdominal pain & 1 & - & - & - & 1 & - & - & - & - & 2 & - & - & 4 & (27) & - & - \\
\hline Chest pain & - & 1 & - & 1 & - & - & - & - & - & 1 & - & - & 3 & (20) & 2 & $(40)$ \\
\hline Vomiting & - & - & - & - & - & - & 2 & - & - & - & 1 & - & 3 & (20) & 1 & (20) \\
\hline $\begin{array}{l}\text { Alkaline phosphatase } \\
\text { increased }\end{array}$ & 1 & - & - & 1 & - & - & 3 & - & - & 1 & - & - & 6 & $(40)$ & 2 & (40) \\
\hline Albumin decreased & - & - & - & - & 1 & - & 4 & - & - & - & 1 & - & 6 & $(40)$ & - & - \\
\hline $\begin{array}{l}\text { Alanine aminotransferase } \\
\text { increased }\end{array}$ & 1 & - & - & - & - & - & 2 & - & - & - & - & - & 3 & (20) & 3 & $(60)$ \\
\hline Total protein decreased & - & - & - & - & - & - & 3 & - & - & - & - & - & 3 & $(20)$ & - & - \\
\hline Arrhythmia & - & - & - & - & - & - & - & - & 1 & - & - & - & 1 & (7) & 1 & $(20)$ \\
\hline Anemia & - & - & - & - & - & - & - & - & 1 & - & - & - & 1 & (7) & - & - \\
\hline Thrombocytopenia & & - & - & - & - & - & - & - & 1 & - & - & - & 1 & (7) & - & - \\
\hline
\end{tabular}

$G$ common toxicity criteria grade 1 is mild, a grade 2 is moderate, and grade 3 is severe

* The advanced events listed here were reported in $>20 \%$ of patients and the grade 3 events of patient

** Number of patients with drug-related adverse events after 28 days $\left(200 \mathrm{mg} / \mathrm{m}^{2}\right.$ bid; $\left.N=1,400 \mathrm{mg} / \mathrm{m}^{2} \mathrm{bid} ; N=1,800 \mathrm{mg} / \mathrm{m}^{2} \mathrm{bid} ; N=3\right)$
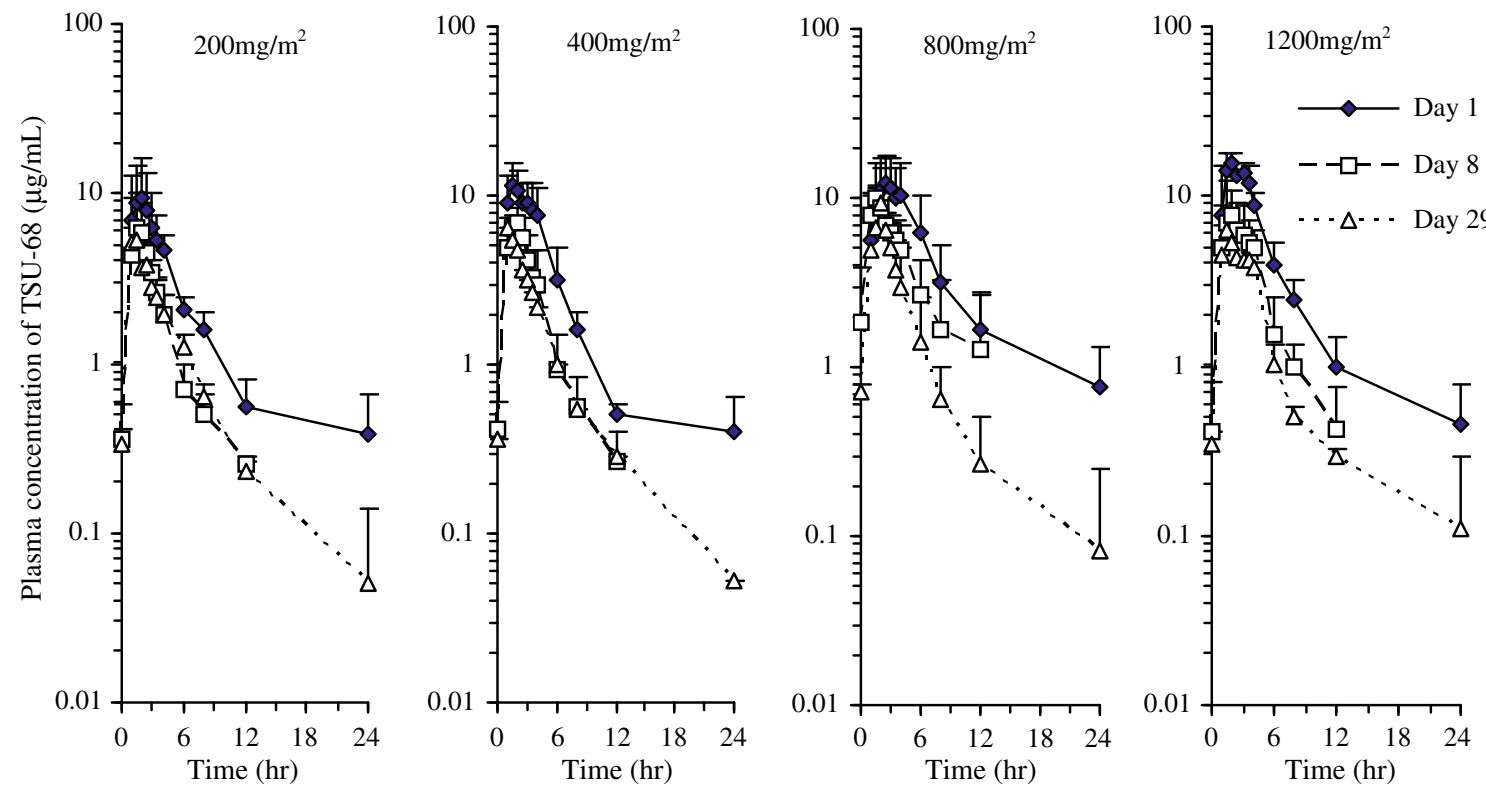

Fig. 1 Plasma concentration-versus-time profile of TSU-68 
Table 3 Pharmacokinetic parameters of TSU-68 after day 1 , day 8 , or day 29 administration
$* 2$ patients, $* * 5$ patients, *** 4 patients

Fig. 2 Effect of dose on the $\mathrm{C}_{\max }$ and $\mathrm{AUC}$

\begin{tabular}{lrlccl}
\hline PK Parameter & $\begin{array}{l}\text { Dose } \\
\left(\mathrm{mg} / \mathrm{m}^{2}\right)\end{array}$ & $\begin{array}{l}\text { Pts. } \\
\text { no. }\end{array}$ & \multicolumn{1}{l}{ Day 1} & Day 8 & Day 29 \\
\hline $\mathrm{T}_{\max }(\mathrm{h})$ & 200 & 3 & $2.3 \pm 1.5$ & $1.7 \pm 0.3$ & $1.7 \pm 0.8$ \\
& 400 & 3 & $2.5 \pm 1.3$ & $1.8 \pm 0.3$ & $1.0^{*}$ \\
& 800 & 6 & $2.8 \pm 1.1$ & $1.5 \pm 0.4 * *$ & $2.1 \pm 0.3 * * *$ \\
& 1,200 & 3 & $2.2 \pm 0.8$ & $1.8 \pm 0.3$ & $1.7 \pm 0.3$ \\
$\mathrm{C}_{\max }(\mu \mathrm{g} / \mathrm{mL})$ & 200 & 3 & $10.552 \pm 6.042$ & $6.669 \pm 3.698$ & $6.354 \pm 3.775$ \\
& 400 & 3 & $11.667 \pm 3.807$ & $7.212 \pm 1.060$ & $6.351^{*}$ \\
& 800 & 6 & $14.620 \pm 5.649$ & $10.564 \pm 1.831^{* *}$ & $10.732 \pm 4.690^{* * *}$ \\
& 1,200 & 3 & $16.004 \pm 1.910$ & $8.148 \pm 4.219$ & $6.706 \pm 0.884$ \\
$\mathrm{AUC}_{0-\mathrm{t}}(\mu \mathrm{g} \mathrm{h} / \mathrm{mL})$ & 200 & 3 & $45.6 \pm 21.0$ & $20.6 \pm 6.2$ & $21.2 \pm 9.5$ \\
& 400 & 3 & $58.2 \pm 16.8$ & $25.0 \pm 9.4$ & $22.9 *$ \\
& 800 & 6 & $83.3 \pm 32.7$ & $44.6 \pm 17.3 * *$ & $30.0 \pm 16.7 * * *$ \\
& 1,200 & 3 & $76.6 \pm 1.0$ & $32.9 \pm 16.2$ & $25.8 \pm 2.4$ \\
$\mathrm{~T}_{1 / 2}(\mathrm{~h})$ & 200 & 3 & $8.03 \pm 3.82$ & $4.80 \pm 2.14$ & $3.59 \pm 1.71$ \\
& 400 & 3 & $7.89 \pm 4.04$ & $3.53 \pm 0.43$ & $5.36^{*}$ \\
& 800 & 6 & $9.93 \pm 6.01$ & $4.31 \pm 2.72^{* * *}$ & $4.37 \pm 4.05 * * *$ \\
& 1,200 & 3 & $8.33 \pm 4.65$ & $2.78 \pm 0.90$ & $4.84 \pm 3.29$ \\
\hline
\end{tabular}
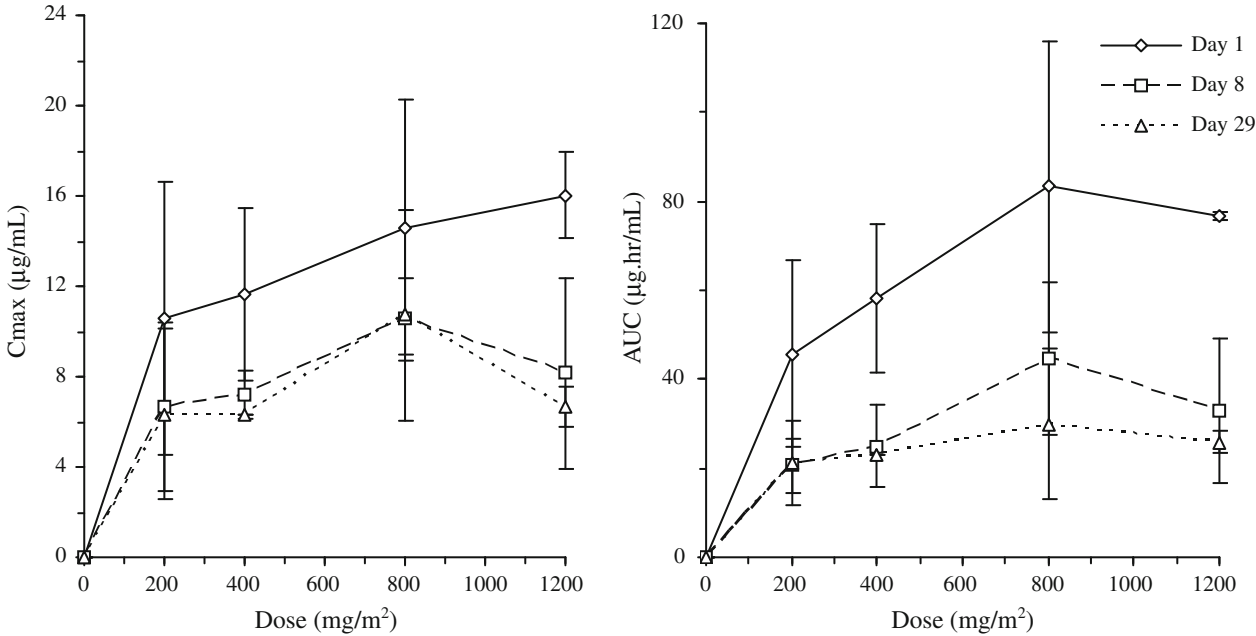

TSU-68 increased to reach $\mathrm{C}_{\max }$ at $\sim 2.5 \mathrm{~h}$ and thereafter disappeared with $\mathrm{T}_{1 / 2}$ in $\sim 8-10 \mathrm{~h}$. At the any dose levels, $\mathrm{C}_{\max }$ and $\mathrm{AUC}_{0-\mathrm{t}}$ after the repeated doses on days 8 and 29 were $\sim 2$-fold lower than those after the first doses on day 1 . These parameters are not statistically different between days 8 and 29. In addition, no obvious dose-dependent increase in plasma exposure to TSU-68 repeatedly administered was observed over the four dose levels, most notably the higher dose levels. Urinary excretion of TSU-68 was below $1 \%$ of dose at the any dose levels.

\section{Response}

No partial or complete responses were seen. One patient with adenocarcinoma of the lung had a minor response by 4 week treatment (Fig. 3) and continued 3 months, but after that the treatment discontinued because of tumor progression and drug-related toxicity. The increased effusion was confirmed non-malignant, and this event was considered a drug-related toxicity. The size of the target lesion reduced from $5.5 \mathrm{~cm} \times 5.0 \mathrm{~cm}$ of the base line to $4.5 \mathrm{~cm} \times 4.3 \mathrm{~cm}$ of 4 week treatment (29.6\% reduction). Reduction of tumor marker levels was seen in the same patient (CEA $22.6 \rightarrow 12.6 \mathrm{ng} / \mathrm{ml}$, SLX $74 \rightarrow 58 \mathrm{U} / \mathrm{ml})$. Four patients had stable disease (non-small cell lung cancer 2; thymoma 1; peritoneal sarcoma 1) and continued treatment over two cycles until disease progression (until 5 cycle for patients with peritoneal sarcoma and 2 cycles for the rest of the patients).

In the angiogenesis-related biomarker of the six tested factors with 14 patients, not including one patient of DLT, 
Fig. 3 Computed tomography scan of a tumor minor shrinkage in a patient with adenocarcinoma of the lung, and pleural effusion progression, treated with TSU-68. a Baseline; b week 4 . White arrow primary tumor in the lung
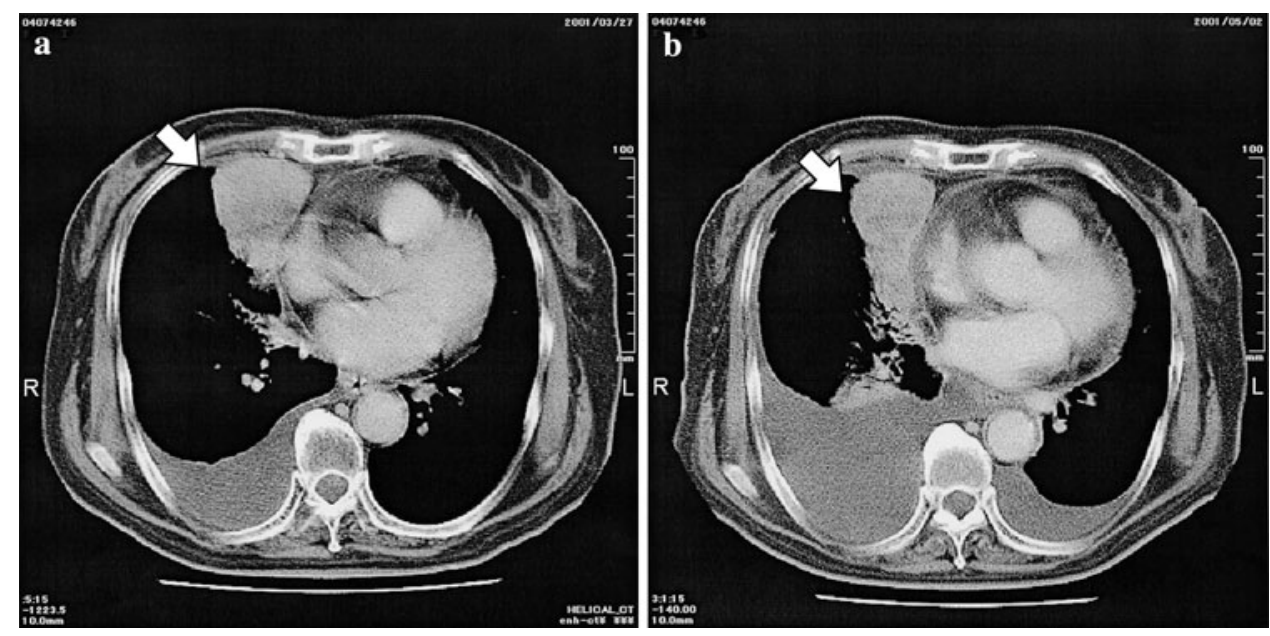

an average of PAI-1 and urine VEGF saw an increase of more than $20 \%$ over the baseline (from $24.3 \pm 6.7 \mathrm{ng} / \mathrm{ml}$ to $29.5 \pm 11.3 \mathrm{ng} / \mathrm{mL}$ and from $96.6 \pm 62.4 \mathrm{pg} / \mathrm{ml}$ to $132.1 \pm$ $93.6 \mathrm{pg} / \mathrm{mL}$, respectively), but plasma VEGF, E-selectin, tPA and VCAM-1 were not changed substantially.

\section{Discussion}

We performed a phase I and pharmacokinetic study to explore safety, tolerated dose, and pharmacokinetics of the oral multiple tyrosine kinase inhibitor TSU-68 in Japanese patients with advanced solid tumors. In this study using continuous oral bid administration between meals, side effects attributable to the study drug were subjective/objective symptom and abnormal changes in laboratory values, whereas DLT included arrhythmia.

The subjective and objective symptom toxicities of TSU-68 in our current study were predominantly gastrointestinal and consisted of dose-dependent, non-cumulative, and reversible diarrhea, fatigue, anorexia, and abdominal pain. At lower dose levels, these symptoms were mild and needed no additional treatment. At the highest dose level, 2 patients discontinued the treatment over 4 weeks for intolerable fatigue and abdominal pain, respectively (Table 2). Some patients with abdominal pain were given gastrointestinal endoscopy, but no remarkable finding was observed. It was considered a reasonable assessment to stop the dose escalation under grade 2 fatigue and grade 2 abdominal pain at a dosage level of $1,200 \mathrm{mg} / \mathrm{m}^{2}$ bid, because of unacceptable adverse events for an antitumor drug that is used in long-term consecutive oral administration.

In 7 patients, edema and/or pleural effusion progression were seen as dose independent (for example: Fig. 3). Edema was remarkable on the face and eyelids. In addition, 11 patients experienced hypoalbuminemia dose dependently. Although this was seen from an early period, it improved immediately after therapy discontinuance. Although VEGF is also known as a vascular permeability factor [20,21], the contribution of VEGF is unclear with no significant difference between patients with edema or effusion progression and patients without. VEGF level in pleural effusion was not elevated in some patients (data not shown). On the other hand, there is a possible contribution of PDGF in this phenomenon based on the report that edema was seen in about $40 \%$ patients including $7 \%$ grade $3 / 4$ treated with Imatinib, which is an inhibitor of $\mathrm{Bcr} / \mathrm{Abl}$ tyrosine kinase and PDGF/Kit tyrosine kinase and approved for chronic myeloid leukemia, Philadelphia chromosome positive acute lymphoblastic leukemia and gastrointestinal stromal tumor [22-24]. It was also reported that PDGF levels of pleural effusion with lung cancer were higher than in non-malignant pleural effusions [25].

Six patients experienced tumor pain progression such as chest pain from primary or metastatic lung cancer. This may be due to drug intake, because tumor pain was diminished after being taken off the drug. To clarify the mechanism of these symptoms, additional studies including basic research are needed.

The hematologic toxicity of TSU-68 in the current study was considered dose independent. Grade 3 anemia and thrombocytopenia were seen in the same patient at $800 \mathrm{mg} /$ $\mathrm{m}^{2}$ dose level. Thrombocytopenia was recovered to pretreatment level after treatment discontinuance, but anemia continued. This patient was given radiotherapy after 9 days due to bone metastasis. Therefore, anemia was not attributed to TSU-68 intake but tumor progression.

These toxicity findings, characterized as edema, were much different from the reports of recent approved and developing angiogenesis inhibitors showing bleeding, perforation, hypertension, hand-foot syndrome, and some leukocytopenia as the distinguishing toxicity profile [26-28].

In the pharmacokinetics, the $\mathrm{C}_{\max }$ and AUC were similar between days 8 and 29, although decreased by half after the 
repeated administration of TSU-68. This suggests that the decreased plasma exposure to TSU-68 rapidly reaches the steady state and is maintained over therapeutic cycles. This trend is consistent with a published clinical result showing that AUC of TSU-68 on day 56 was similar to that on day 28 [29]. In addition, at the higher dose levels, there was no dose-dependent increase in these parameters of TSU-68 repeatedly administered, which is probably due to a saturation of absorption. The trough plasma level in the steadystate exposure to $200 \mathrm{mg} / \mathrm{m}^{2}$ TSU-68 is above the IC50 for VEGF and PDGF receptors cellular assay, and the exposure was also comparable with that showing efficacy in human cancer xenograft models [16]. The decrease in the exposure after repeated administration is probably due to autoinduction of TSU-68 metabolism. Since urinary excretion accounted for a very low percentage of the dose, predominant elimination of TSU-68 can be regarded as hepatic metabolism. Non-clinical studies [30, 31] suggest that TSU-68 causes induction of liver cytochrome P450, CYP1A1/2 involved in its own metabolism, leading to the decrease in the TSU-68 plasma concentrations.

A phase I study of the United States was reported before our Japanese study. Nineteen Caucasian patients were treated at doses ranging from $400-1,200 \mathrm{mg} / \mathrm{m}^{2}$ fasted and $100-400 \mathrm{mg} / \mathrm{m}^{2}$ fed by twice daily administration [32]. Dose-limiting toxicities including fatigue, pleuritic chest pain, shortness of breath, and pericardial effusions were seen in 2 patients. The AUC declined from $70 \mu \mathrm{g} . \mathrm{h} / \mathrm{ml}$ on day 1 to $32 \mu \mathrm{g} . \mathrm{h} / \mathrm{ml}$ on day 28 . The results for TSU-68 in Japanese patients demonstrated a similar toxicity and pharmacokinetics profile to Caucasian patients.

Antitumor effect was observed in some patients in this clinical study. One patient with adenocarcinoma of the lung had a minor tumor shrinkage and reduction of tumor marker levels. In addition, four patients had no disease progression after one cycle treatment. Although angiogenesis inhibitors such as TSU-68 have been thought to have little or no tumor shrinkage, some drugs showed obvious tumor regression.

Although the primary objective of phase I clinical trial is not to see response but to determine recommended dose for phase II clinical trial, tumor response is thought to be an important factor. Therefore, further studies using this agent are expected. MTD was not reached in this study, because DLT was only seen in one patient at $800 \mathrm{mg} / \mathrm{m}^{2}$. We suggest the highest dose level was not the tolerable dose, because two patients discontinued the treatment for drugrelated toxicities in spite of their being low grade. In addition, pharmacokinetic data of this level showed no significant difference compared with other dose levels, and no dose-dependent increase on days 8 and 29.

In conclusion of this phase I and pharmacokinetic study with continuous oral bid between meals, TSU-68 has shown that a multiple receptor tyrosine kinase inhibitor can be safely administered. The recommended dose for further studies using this treatment schedule is less than $800 \mathrm{mg} / \mathrm{m}^{2}$ bid.

Acknowledgments We thank Terumi Sakamoto, Tsuneo Suzuki, Taro Furuie, Kenzo Iizuka, Toyomitsu Sato, Kumio Aoyagi, Junichi Yonezawa, Yoshio Yamamoto, and Ryuichi Kitamura for assistant in data collection and analysis. We are also grateful to Yutaka Ariyoshi, Nagahiro Saijo, and Yuh Sakata for extramural review.

Open Access This article is distributed under the terms of the Creative Commons Attribution Noncommercial License which permits any noncommercial use, distribution, and reproduction in any medium, provided the original author(s) and source are credited.

\section{References}

1. Toi M, Hoshina S, Takayanagi T, Tominaga T (1994) Association of vascular endothelial growth factor expression with tumor angiogenesis and with early relapse in primary beast cancer. Jpn $\mathrm{J}$ Cancer Res 85:1045-1049

2. Maeda K, Chung YS, Ogawa Y, Takatsuka S, Kang SM, Ogawa M, Sawada T, Sowa M (1996) Prognostic value of vascular endothelial growth factor expression in gastric carcinoma. Cancer 77:858-863

3. Takahashi Y, Kitadai Y, Bucana CD, Cleary KR, Ellis LM (1995) Expression of vascular endothelial growth factor and its receptor, KDR, correlates with vascularity, metastasis, and proliferation of human colon cancer. Cancer Res 55:3964-3968

4. Giatromanolaki A, Koukourakis MI, Kakolyris S, Turley H, O’Byrne K, Scott PA, Pezzella F, Georgoulias V, Harris AL, Gatter KC (1998) Vascular endothelial growth factor, wild-type p53, and angiogenesis in early operable non-small cell lung cancer. Clin Cancer Res 4:3017-3024

5. Kim KJ, Li B, Houck K, Winer J, Ferrara N (1993) Inhibition of vascular endothelial growth factor-induced angiogenesis suppresses tumor growth in vivo. Nature 362:841-844

6. Hu-Lowe DD, Zou HY, Grazzini ML, Hallin ME, Wickman GR, Amundson K, Chen JH, Rewolinski DA, Yamazaki S, Wu EY, McTigue MA, Murray BW, Kania RS, O'Connor P, Shalinsky DR, Bender SL (2008) Nonclinical antiangiogenesis and antitumor activities of axitinib (AG-013736), an oral, potent, and selective inhibitor of vascular endothelial growth factor receptor tyrosine kinases 1, 2, 3. Clin Cancer Res 14:7272-7283

7. Bikfalvi A, Klein S, Pintucci G, Rifkin DB (1997) Biological roles of fibroblast growth factor-2. Endocr Rev 18:26-45

8. Yamaguchi F, Saya H, Bruner JM, Morrison RS (1994) Differential expression of two fibroblast growth factor-receptor genes is associated with malignant progression in human astrocytomas. Proc Natl Acad Sci USA 91:484-488

9. Seghezzi G, Patel S, Ren CJ, Gualandris A, Pintucci G, Robbins ES, Shapiro RL, Galloway AC, Rifkin DB, Mignatti P (1998) Fibroblast growth factor-2 (FGF-2) induces vascular endothelial growth factor (VEGF) expression in the endothelial cells of forming capillaries: an autocrine mechanism contributing to angiogenesis. J Cell Biol 141:1659-1673

10. Plate KH, Breier G, Farrell CL, Risau W (1992) Platelet-derived growth factor receptor-beta is induced during tumor development and upregulated during tumor progression in endothelial cells in human gliomas. Lab Invest 67:529-534

11. Lindmark G, Sundberg C, Glimelius B, Pahlman L, Rubin K, Gerdin B (1993) Stromal expression of platelet-derived growth factor beta-receptor and platelet-derived growth factor B-chain in colorectal cancer. Lab Invest 69:682-689 
12. Rosenkranz S, Kazlauskas A (1999) Evidence for distinct signaling properties and biological responses induced by the PDGF receptor a and b subtypes. Growth Factors 16(3):201-216

13. Sato N, Beitz JG, Kato J, Yamamoto M, Clark JW, Calabresi P, Raymond A, Frackelton AR Jr (1993) Platelet-derived growth factor indirectly stimulates angiogenesis in vitro. Am J Pathol 142:1119-1130

14. Ariad S, Seymour L, Bezwoda WR (1991) Platelet-derived growth factor (PDGF) in plasma of breast cancer patients: correlation with stage and rate of progression. Breast Cancer Res Treat 20:11-17

15. Anan K, Morisaki T, Katano M, Ikubo A, Kitsuki H, Uchiyama A, Kuroki S, Tanaka M, Torisu M (1996) Vascular endothelial growth factor and platelet-derived growth factor are potential angiogenic and metastatic factors in human breast cancer. Surgery 119:333-339

16. Laird AD, Vajkoczy P, Shawver LK, Thurnher A, Liang C, Mohammadi M, Schlessinger J, Ullrich A, Hubbard SR, Blake RA, Fong TA, Strawn LM, Sun L, Tang C, Hawtin R, Tang F, Shenoy N, Hirth KP, McMahon G, Cherrington JM (2000) SU6668 is a potent antiangiogenic and antitumor agent that induces regression of established tumors. Cancer Res 60:4152-4160

17. Shaheen RM, Davis DW, Liu W, Zebrowski BK, Wilson MR, Bucana CD, McConkey DJ, McMahon G, Ellis LM (1999) Antiangiogenic therapy targeting the tyrosine kinase receptor for vascular endothelial growth factor receptor inhibits the growth of colon cancer liver metastasis and induces tumor and endothelial cell apoptosis. Cancer Res 59:5412-5416

18. Japan Clinical Oncology Group (1999) National cancer institutecommon toxicity criteria version 2.0, Japanese translations first version. Jpn J Cancer Chemother 26:1084-1144

19. Japan Society Cancer Therapy (1993) Criteria for the evaluation of the clinical effects of solid cancer chemotherapy. J Japn Soc Cancer Ther 28:101-130

20. Yano S, Herbst RS, Shinohara H, Knighton B, Bucana CD, Killion JJ, Wood J, Fidler IJ (2000) Treatment for malignant pleural effusion of human lung adenocarcinoma by inhibition of vascular endothelial growth factor receptor tyrosine kinase phosphorylation. Clin Cancer Res 6:957-965

21. Zebrowski BK, Yano S, Liu W, Shaheen RM, Hicklin DJ, Putnam JB Jr, Ellis LM (1999) Vascular endothelial growth factor levels and induction of permeability in malignant pleural effusions. Clin Cancer Res 5:3364-3368

22. Druker BJ, Talpaz M, Resta DJ, Peng B, Buchdunger E, Ford JM, Lydon NB, Kantarjian H, Capdeville R, Ohno-Jones S, Sawyers CL (2001) Efficacy and safety of a specific inhibitor of the BCRABL tyrosine kinase in chronic myeloid leukemia. N Engl J Med 344:1031-1037
23. Druker BJ, Sawyers CL, Kantarjian H, Resta DJ, Reese SF, Ford JM, Capdeville R, Talpaz M (2001) Activity of a specific inhibitor of the BCR-ABL tyrosine kinase in the blast crisis of chronic myeloid leukemia and acute lymphoblastic leukemia with the Philadelphia chromosome. N Engl J Med 344:1038-1042

24. van Oosterom AT, Judson I, Verweij J, Stroobants S, Donato di Paola E, Dimitrijevic S, Martens M, Webb A, Sciot R, Van Glabbeke M, Silberman S, Nielsen OS et al (2001) Safety and efficacy of imatinib (STI571) in metastatic gastrointestinal stromal tumours: a phase I study. Lancet 358:1421-1423

25. Safi A, Sadmi M, Martinet N, Menard O, Vaillant P, Gallati H, Hosang M, Martinet Y (1992) Presence of elevated levels of platelet-derived growth factor (PDGF) in lung adenocarcinoma pleural effusions. Chest 102:204-207

26. Gordon MS, Margolin K, Talpaz M, Sledge GW Jr, Holmgren E, Benjamin R, Stalter S, Shak S, Adelman D (2001) Phase I safety and pharmacokinetic study of recombinant human anti-vascular endothelial growth factor in patients with advanced cancer. J Clin Oncol 19:843-850

27. Faivre S, Delbaldo C, Vera K, Robert C, Lozahic S, Lassau N, Bello C, Deprimo S, Brega N, Massimini G, Armand JP, Scigalla P, Raymond E (2006) Safety, pharmacokinetic, and antitumor activity of SU11248, a novel oral multi target tyrosine kinase inhibitor, in patients with cancer. J Clin Oncol 24:25-35

28. Clark JW, Eder JP, Ryan D, Lathia C, Lenz HJ (2005) Safety and pharmacokinetics of the dual action Raf kinase and vascular endothelial growth factor receptor inhibitor, BAY 43-9006, in patients with advanced, refractory solid tumors. Clin Cancer Res 11:54725480

29. Kuenen BC, Giaccone G, Ruijter R, Kok A, Schalkwijk C, Hoekman K, Pinedo HM (2005) Dose-finding study of the multi targeted tyrosine kinase inhibitor SU6668 in patients with advanced malignancies. Clin Cancer Res 11:6240-6246

30. Kitamura R, Yamamoto Y, Nagayama S, Otagiri M (2007) Decrease in plasma concentrations of antiangiogenic agent TSU-68 ((Z)-5[(1,2-dihydro-2-oxo-3H-indol-3-ylidene)methyl]-2, 4-dimethyl$1 \mathrm{H}$-pyrrole-3-propanoic acid) during oral administration twice a day to rats. Drug Metab Dispos 35:1611-1616

31. Kitamura R, Asanoma H, Nagayama S, Otagiri M (2008) Identification of human liver cytochrome P450 isoforms involved in autoinduction of the anti-angiogenic agent TSU-68 ((Z)-5-[(1, 2dihydro-2-oxo-3H-indol-3-ylidene)methyl]-2,4-dimethyl-1H-pyrrole-3-propanoic acid). Drug Metab Dispos 36:1003-1009

32. Brahmer JR, Kelsey S, Scigalla P, Hill G, Bello C, Elza-Brown K, Donehower R (2002) A phase I study of SU6668 in patients with refractory solid tumors. Proc Am Soc Clin Oncol 21:335 